\title{
Experience on divertor fuel retention after two ITER-Like Wall campaigns
}

K. Heinola ${ }^{1 *}$, A. Widdowson ${ }^{2}$, J. Likonen ${ }^{3}$, T. Ahlgren ${ }^{1}$, E. Alves ${ }^{4}$, C. F. Ayres ${ }^{2}$, A. Baron-Wiechec $^{2}$, N. Barradas ${ }^{5}$, S. Brezinsek ${ }^{6}$, N. Catarino ${ }^{4}$, P. Coad ${ }^{2}$, C. Guillemaut ${ }^{4}$ I.

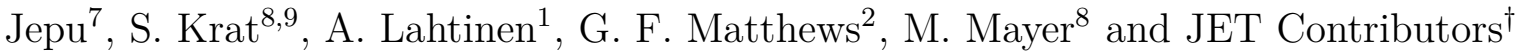

EUROfusion Consortium, JET, Culham Science Centre, Abingdon, OX14 3DB, UK

${ }^{1}$ Department of Physics, University of Helsinki, P.O. Box 64, 00560 Helsinki, Finland ${ }^{2}$ CCFE, Culham Science Centre, Abingdon, OX14 3DB, UK

${ }^{3}$ VTT, P.O. Box 1000, 02044 VTT, Espoo, Finland

${ }^{4}$ Instituto Superior Tecnico, Instituto de Plasmas e Fusao Nuclear, Universidade de Lisboa, 1049-001, Lisboa, Portugal

${ }^{5}$ Centro de Ciencias e Tecnologias, Nucleares Instituto Superior Tecnico, Universidade de Lisboa, 2695-066 Bobadela, Portugal ${ }^{6}$ Forschungszentrum Julich GmbH, D-52425, Julich, Germany ${ }^{7}$ National Institute for Laser, Plasma and Radiation Physics, Bucharest-Magurele 077125, Romania ${ }^{8}$ Max-Planck Institut fur Plasmaphysik, D-85748, Garching, Germany and ${ }^{9}$ National Research Nuclear University MEPhl, 115409 Moscow, Russia

* Corresponding author Email: kalle.heinola@helsinki.fi

$\dagger$ See the author list of X. Litaudon et al. Nucl. Fusion 57, 102001 (2017) 


\begin{abstract}
The JET ITER-Like-Wall experiment with its all-metal plasma-facing components provides a unique environment for plasma and plasma-wall interaction studies. These studies are of great importance in understanding the underlying phenomena taking place during the operation of a future fusion reactor. Present work summarizes and reports the plasma fuel retention in the divertor resulting from the two first experimental campaigns with the ITER-Like Wall. The deposition pattern in the divertor after the second campaign shows same trend as was observed after the first campaign: highest deposition of $10-15 \mu \mathrm{m}$ was found on top part of the inner divertor. Due to the change in plasma magnetic configurations from the first to the second campaign, and the resulted strike point locations, an increase of deposition was observed on the base of the divertor. The deuterium retention was found to be affected by the hydrogen plasma experiments done at the end of second experimental campaign.
\end{abstract}

PACS numbers: 28.52.Fa 52.55.Fa 52.55.Pi 52.70.Nc 52.77.Dq 


\section{INTRODUCTION}

The JET tokamak with its ITER-Like Wall (ILW) project [1] provides a unique opportunity to study the plasma-material interactions (PMI) taking place in operating the next-step fusion device ITER. In ILW, the main chamber limiters comprise of bulk beryllium (Be), and the divertor consists of armour tiles of either bulk tungsten (W), or W-coated carbon-fibre composite (CFC) tiles. Removal and replacement of these plasma-facing components (PFC) during shutdown phases of JET allow post-campaign, or post-mortem, analyses to scrutinize the campaign integrated net effects of the PMIs. This work summarizes the present results on fuel retention and deposit formation after two ILW campaigns.

Gas balance measurements performed during the first operational phase of JET-ILW in 2011-2012 (ILW-1) have shown a factor 10-20 reduction in the long-term fuel retention measurements as compared to the operational period 2007-2009 with an all-Carbon wall (JET-C) [2]. The ILW-1 post-mortem analyses of the PFCs retrieved from the JET vessel during the shutdown 2013 mapped the global distribution of the deposits and fuel retention inside the machine ([3-8] and references therein). The global fuel retention rate was found to have decreased in ILW-1 by a factor $>18$ as compared to JET-C [5]. Also, the results showed the chemistry affecting the erosion and deposit migration when changing from JETC to JET-ILW: the deposit formation in ILW does not appear to proceed via long range migration of the eroded particles due to lack of enhanced re-erosion. The highest amounts of metallic deposits were found on top of the inner divertor, whereas in JET-C the thickest $\mathrm{C}$ deposits were formed in the base of the divertor due to enhanced re-erosion processes by chemical sputtering [3].

The second ILW campaign in 2013-2014 (ILW-2) had similar characteristics to ILW-1, but focused on high power, high density plasma scenarios. A general review on the two ILW campaigns, and on the corresponding shutdown activities are given in Refs. [9] and [10], respectively. The ILW-2 fuel retention post-mortem analyses took place after receiving samples during the JET shutdown 2015, and the first results have been published in Refs. [11-13]. In the present work, the main findings from the ILW-1 and ILW-2 post-mortem results on fuel retention and deposition formation in the divertor are reviewed, and the effect of the plasma operations are discussed. 


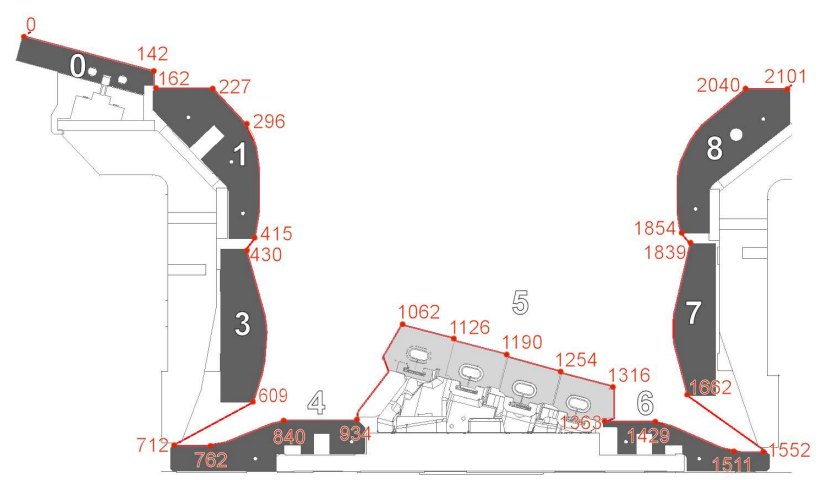

FIG. 1: (Color online) Poloidal cross-section of the ILW divertor. The divertor tiles are numbered (white), and their poloidal locations and geometries are described with divertor S coordinate system (red; in mm's). The W-coated CFC tiles $(0,1,3,4,6,7$, and 8$)$ are highlighted in dark grey, and the bulk W tile (5) in light grey.

\section{EXPERIMENTAL}

\section{A. JET ITER-Like Wall campaigns}

The main plasma operation parameters for ILW-1 (pulse numbers 79854-83794) and ILW2 (pulse numbers 83933-87944) are presented in Table I. The total plasma time was approximately identical for both campaigns, but the limiter configuration time was slightly lower in ILW-2 $(\sim 5 \mathrm{hrs})$ than in ILW-1 $(\sim 6 \mathrm{hrs})$, and the divertor configuration time was higher in ILW-2 ( 14 hrs) than in ILW-1 ( 13 hrs). Both ILW campaigns operated with deuterium (D) plasmas. However, the ILW-2 was finished with a dedicated two-week campaign with hydrogen $(\mathrm{H})$ plasmas $(0.6 \mathrm{hrs})$.

Fig. 1 shows the poloidal cross-section of the ILW divertor, and highlights all the plasmafacing divertor tiles. The plasma strike point distributions on the divertor tiles during ILW-1 and ILW-2 are shown in Fig. 2. The inner divertor strike point (ISP) was mainly on Tile 3 in ILW-1, and on Tile 4 in ILW-2. The outer divertor strike point (OSP) in ILW-1 was mainly in the center tile of divertor on Tile 5, and in ILW-2 it was targeted predominantly on Tile 6.

The amount of puffed D was increased with more than a factor of two in ILW-2. Moreover, the total amount of seeded impurities (N, Ne, Ar) was increased with more than an order of magnitude from ILW-1 to ILW-2. In ILW-1 there were fewer high current, high power 


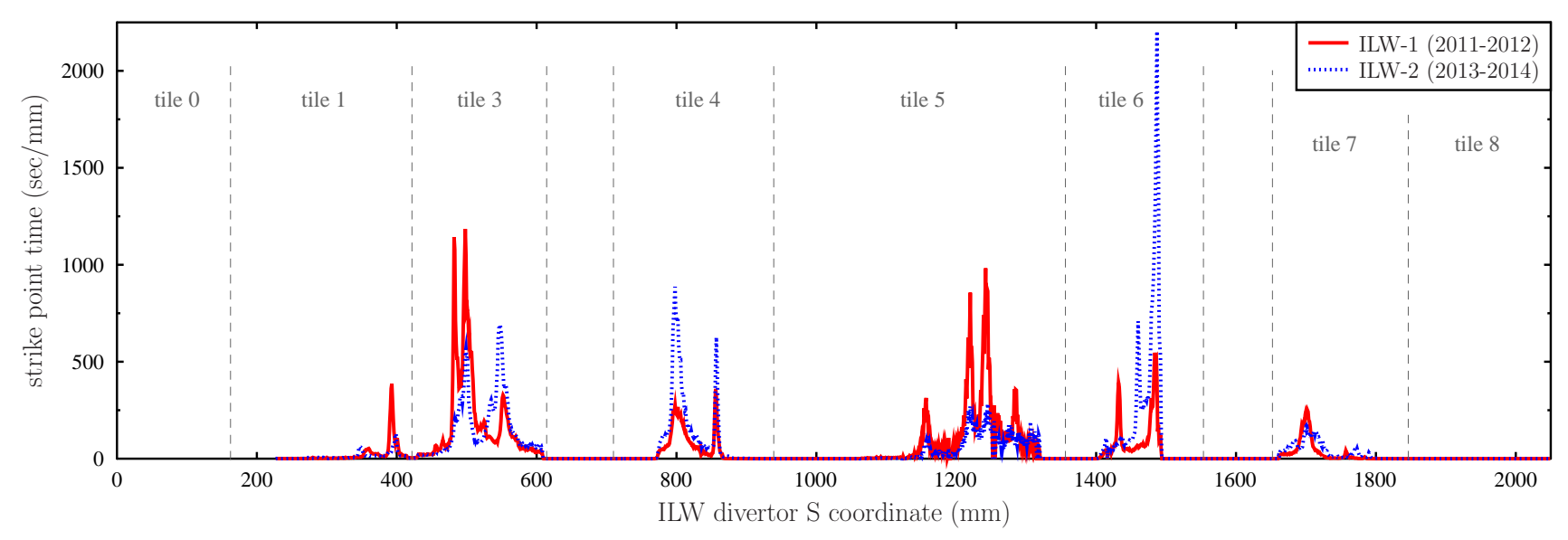

FIG. 2: The plasma strike point residence times in the ILW divertor during the ILW-1 and ILW-2 campaigns as a function of the divertor S coordinate. Corresponding tile locations highlighted.

pulses with currents up to $3.5 \mathrm{MA}$, magnetic fields up to $3.2 \mathrm{~T}$, and Neutral Beam Injection (NBI) power up to $26 \mathrm{MW}$ in conjuction with Ion Cyclotron Heating Resonance Heating (ICRH) up to $3.5 \mathrm{MW}$ [14]. The averaged input power was $2.35 \mathrm{MW}$ and the total input energy 150 GJ. In ILW-2 higher number of high current, high power pulses were used with plasma currents up to $4 \mathrm{MA}$, magnetic field up to $3.7 \mathrm{~T}$, NBI and ICRH up to 27 and 7 MW, respectively, and Lower Hybrid Current Drive Drive heating up to 3 MW [15]. The averaged input power and the total input energy was $2.82 \mathrm{MW}$ and 200 GJ, respectively, resulting to a corresponding increase of $20 \%$ and $33 \%$ when compared to ILW-1. There was an overall increase in the absorbed energies at the divertor tiles in ILW-2. Tiles 4, 6 and 7 had a maximum increase nearly by a factor of four, whereas the energy deposited on Tiles 1 and 3 increased by $16 \%$.

\section{B. Post-mortem analyses}

\section{Experimental methods}

The ILW divertor comprises of W-coated CFC tiles, and of a bulk W tile (Fig. 1). A special selection of W-coated CFC tiles used in this work have a Mo marker interlayer coating for accurate erosion/deposition studies: a layered coating with a W/Mo/W/Mo/CFC structure, and thicknesses (in $\mu \mathrm{m}$ ) of $4 / 4 / 12 / 3 /$ bulk. In addition to the standard bulk W 
Tile 5's used for analyses, special Mo marker coated bulk W tiles were prepared for the Tile 5 erosion/deposition studies [13].

The post-mortem methodologies applied for both ILW-1 and ILW-2 tile analyses are Ion Beam Analysis (IBA), Thermal Desorption Spectrometry (TDS), and Secondary Ion Mass Spectrometry (SIMS). In IBA, the Nuclear Reaction Analysis (NRA) was used for determining the $\mathrm{D}$ concentrations with the $\mathrm{D}\left({ }^{3} \mathrm{He}, \mathrm{p}\right){ }^{4} \mathrm{He}$ nuclear reaction. With NRA also the Be, C impurity concentrations were evaluated with the ${ }^{9} \mathrm{Be}\left({ }^{3} \mathrm{He}, \mathrm{p}\right){ }^{11} \mathrm{~B}$ and ${ }^{12} \mathrm{C}\left({ }^{3} \mathrm{He}, \mathrm{p}\right){ }^{14} \mathrm{~N}$ reactions, respectively. Oxygen $(\mathrm{O})$ was determined by using non-Rutherford scattering cross-sections. The energies used for the ${ }^{3} \mathrm{He}$ ion beam was either $4.5 \mathrm{MeV}$, or $2.3 \mathrm{MeV}$. The use of higher ${ }^{3} \mathrm{He}$ energy $4.5 \mathrm{MeV}$ enables $\mathrm{D}$ and Be concentration analysis to larger depths, and improves the $\mathrm{C}$ and $\mathrm{O}$ detection efficiency as the reaction cross-sections increase with projectile ion energy. The $4.5 \mathrm{MeV}$ NRA results were analyzed the SIMNRA package [16], and the analysis setup is described in Refs. [7, 17]. In conjuction with the $2.3 \mathrm{MeV}{ }^{3} \mathrm{He}$ ion beam for NRA, the Elastic Backscattering (EBS) and Particle Induced X-ray Emission (PIXE) were used for detecting Be and heavier elements. The 2.3 MeV NRA, EBS, and PIXE results were fitted parallelly with WiNDF data furnace software package [18], and the experimental setups are described in detail in Refs. [3, 4, 12].

SIMS analysis was performed for studying the D, Be, C and heavier metallic impurity depth profile concentrations in the ILW divertor samples. The details for the SIMS setup are presented in Refs. [11, 19]. Calibration was done for D by using D-implanted reference samples, which were prepared by implanting $60 \mathrm{keV} / \mathrm{D}_{2}$ into polycrystalline $\mathrm{W}$, Mo and Be (see details in [20]). The retained D in the implantation-induced defects in the calibration samples was determined with Elastic Recoil Detection Analysis allowing an absolute calibration value for SIMS.

The TDS analyses were done in an ultra-high vacuum system with a background pressure of $\lesssim 1-2 \times 10^{-9}$ mbar. Samples were annealed from room temperature up to $1000^{\circ} \mathrm{C}$. The released gases (e.g. $\mathrm{H}_{2}, \mathrm{HD}, \mathrm{D}_{2}, \mathrm{DT}, \mathrm{T}_{2}$, and $\mathrm{Be}$ ) were measured as a function of time and annealing temperature with a line-of-sight mounted, triple-filtered quadrupole mass spectrometer with pulse ion counting. The D signal was calibrated with similarly prepared D-implanted reference samples as was used for SIMS. The full results and the details of the experimental setup for TDS are presented in Refs. [6, 21]. 


\section{Analyzed divertor tiles}

A full poloidal set of divertor tiles retrieved after ILW-1 have been analyzed, and the results have been reported extensively in previous publications (Refs. [3-8] and references therein). It was found, that with JET-ILW the D fuel retention process takes place via implantation and co-deposition, whereas in JET-C the D was found in massive C deposits, which covered large areas of the vessel wall. In ILW-1 the highest D retention values were found in regions with the highest deposition. These were located on top of the inner divertor on Tile 0 and on Tile 1 (Fig. 1). Lower retention was obtained in regions with thin impurity layers, or where implantation might be the main retention mechanism, i.e. in the base of divertor (Tiles 4 and 6), and on outer divertor (Tiles 7 and 8).

The analysis of divertor tiles retrieved after the ILW-2 campaign is ongoing [11-13, 21, 22]. This work discusses the results obtained from Tiles 1, 4, and 6, which have been exposed for single experimental campaign ILW-2. These tiles were prioritized in the analysis programme based on the results obtained from ILW-1 (highest deposition on Tile 1), and based on the plasma configuration and the resulted strike point locations on Tile 4 and 6 in ILW-2 (Fig. 2). Moreover, in addition to the divertor tiles being exposed only for ILW-2, tiles being exposed long-term for both ILW-1 and ILW-2 plasmas have been analyzed [11, 21, 22]. Here we report and compare results from the outer divertor (Tiles 6, 7 and 8) to results obtained from outer divertor tiles exposed only for ILW-1.

\section{RESULTS}

\section{A. Inner divertor}

In Fig. 3 are shown the measured poloidal distributions of the main impurities found on Tile 1 as obtained with 4.5 MeV NRA after ILW-1 and ILW-2. The result after ILW1 campaign shows evidently the deposition and the D retention region being on the top horizontal part (apron; $S=162 \ldots 227 \mathrm{~mm})$, and on the upper vertical part $(S=227 \ldots 296$ $\mathrm{mm}$ ) of Tile 1 (Fig. 3(a)). This region is deep in the plasma scrape-off layer (SOL), and the $\mathrm{D}$ fuel is retained via co-deposition. The impurity layer is formed by erosion of the main chamber Be limiters the inner wall mid-plane limiter being the main erosion region $[23,24]$. The eroded particles flow in the SOL and the main deposition takes place on 

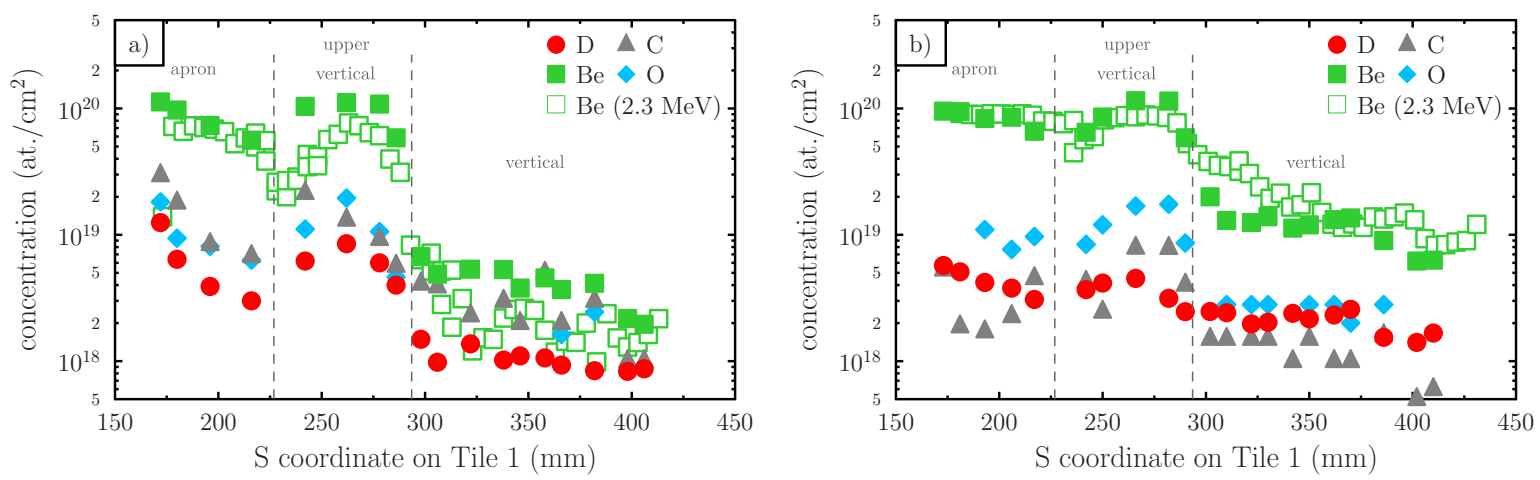

FIG. 3: (Color online) Poloidal distribution of the main impurities on Tile 1 as obtained with NRA using $4.5 \mathrm{MeV}^{3} \mathrm{He}$ beam (also shown the Be result with $2.3 \mathrm{MeV}^{3} \mathrm{He}$ ). Fig. 3(a): NRA after ILW-1. High deposition on the apron $(\mathrm{S}=162 \ldots 227 \mathrm{~mm})$ and on the upper vertical $(\mathrm{S}=227 \ldots 296 \mathrm{~mm})$ surfaces. Significantly lower deposition and D fuel retention in the vertical region $(\mathrm{S}=296 \ldots 415$ mm). Fig. 3(b): NRA after ILW-2. Top part of Tile 1 still with high deposition. A consiberable increase in deposition in the vertical part of tile. The $\mathrm{D}$ fuel retention is found to be almost homogenous along the tile.
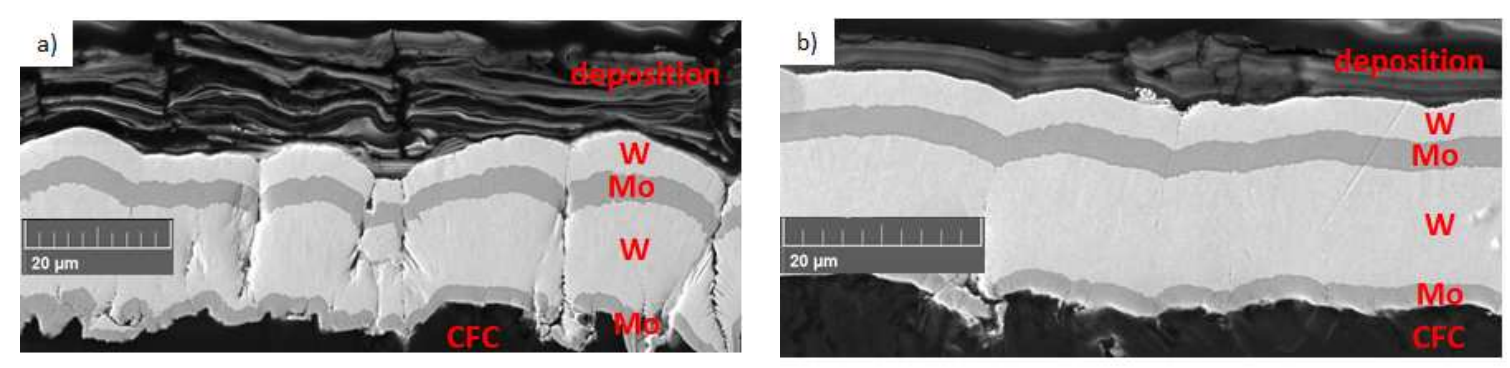

FIG. 4: SEM images on the deposition on Tile 1 apron $(\mathrm{S}=216 \mathrm{~mm})$ after one campaign exposures. Fig. 4(a): After ILW-1 a deposited layer of $10-15 \mu \mathrm{m}$ was formed. The deposition has a sandwichlike layered structure. Fig. 4(b): Formation of the deposited layer in ILW-2 has similar features and thickness as observed with the ILW-1 deposition.

these horizontal surfaces in the upper inner divertor [25]. The thickness of $\sim 10^{20} \mathrm{Be} / \mathrm{cm}^{2}$ corresponds to a deposit thickness of $10-15 \mu \mathrm{m}$, as confirmed with tile profiling [3]. In ILW-1 the ISP was on Tile 3, and in ILW-2 it was predominantly lower in the divertor on Tile 4. This resulted in broadening of the plasma boundary on the inner divertor, which can be seen in the ILW-2 NRA results as a broader impurity distribution along Tile 1: the deposition is extended from the top horizontal part to the vertical region of Tile 1 

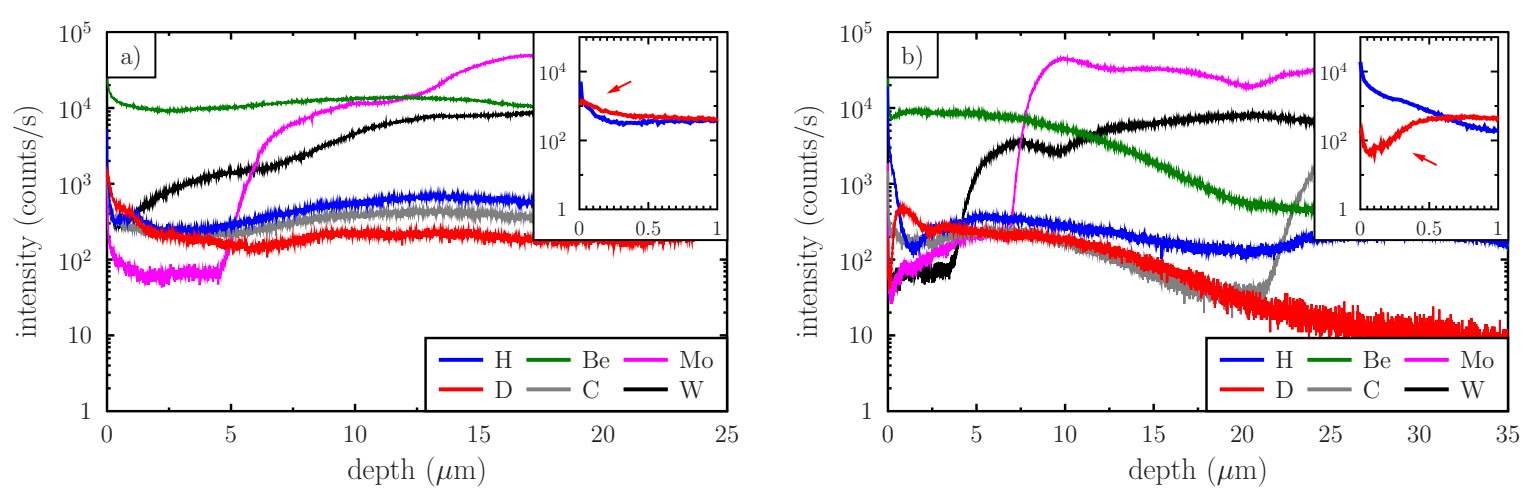

FIG. 5: (Color online) SIMS impurity concentration depth profiles for Tile 1 apron $(\mathrm{S}=216 \mathrm{~mm})$. Fig. 5(a): SIMS profiles after ILW-1. The subfigure shows a high near-surface D retention peak (highlighted by an arrow). Fig. 5(b): SIMS profiles after ILW-2. The near-surface D profile peak is missing (arrow) due to $\mathrm{H}$ co-deposition during the $\mathrm{H}$ plasma campaign in the end of ILW-2. The dip in the shape of the D profile extends up to $\sim 0.5 \mu \mathrm{m}$ from the sample surface.

(Fig. 3(b)) as the wider inner SOL allows particle transport into this area. The broadening of inner SOL nearly doubled the net amount of Be and D in the vertical part of Tile 1 in ILW-2 $\left(S=296 \ldots 415 \mathrm{~mm}: \sim 10^{19} \mathrm{Be} / \mathrm{cm}^{2}, \sim 2 \times 10^{18} \mathrm{D} / \mathrm{cm}^{2}\right)$ as compared to ILW-1 $\left(S=296 \ldots 415 \mathrm{~mm}: \sim 2-5 \times 10^{18} \mathrm{Be} / \mathrm{cm}^{2}, \sim 10^{18} \mathrm{D} / \mathrm{cm}^{2}\right)$. However, the deposition thickness on the top horizontal part (apron) in ILW-2 remained the same as in ILW-1. This is seen also in the SEM images taken from the apron of Tile 1 (Fig. 4): the thickness and the layered sandwich-like structure formation appear to be similar in ILW-1 and in ILW-2. In Fig. 5 is shown the SIMS impurity concentration profiles on the same region on Tile 1 apron as the SEM images. The ILW-1 SIMS profile for D shows a near-surface concentration peak (Fig. 5(a) subfigure). The ILW-2 was finished with a two-week H plasma campaign. The effect of the $\mathrm{H}$ operation can be seen as a near-surface $\mathrm{H}$ concentration in the postmortem SIMS analysis results. Fig. 5(b) shows the ILW-2 D concentration profile having near-surface dip extending up to $\sim 0.5 \mu \mathrm{m}$ in depth. The lack of $\mathrm{D}$ in this region correlates with the $\mathrm{H}$ being co-deposited in this region. Interestingly however, there is no visible $\mathrm{D}$ peak beyond $0.5 \mu \mathrm{m}$ marking the end of the D operation. Thus it may speculated, that the D near-surface peak being potentially present in the end of D operations diminished and was gradually replaced by $\mathrm{H}$ via continuous co-deposition in the course of the $\mathrm{H}$ campaign. However, the extent of an isotopic exchange process remains unresolved, since the divertor 
deposits were affected by this $\mathrm{H}$ co-deposition leading to the formation of the H-rich layers measured with post-mortem analyses. The presence of retained near-surface $H$ is seen in the poloidal D profile on Tile 1 after ILW-2: there are no evident D profile maxima along the tile, and on the top part of the tile $(S=162 \ldots 296 \mathrm{~mm}$; apron and upper vertical region) the $\mathrm{D}$ retention has now similar values than what is found on the vertical region of the tile $(S=296 \ldots 415 \mathrm{~mm})$. The amount of detected D on Tile 1 apron $(S=162 \ldots 227$ $\mathrm{mm})$ after ILW-2 $\left(\sim 4.4 \times 10^{18} \mathrm{D} / \mathrm{cm}^{2}\right)$ is comparable to the amount detected after ILW-1 $\left(\sim 6.5 \times 10^{18} \mathrm{D} / \mathrm{cm}^{2}\right)$ even though the amount of puffed $\mathrm{D}$ was two times higher in ILW-2 than in ILW-1 and the parameters influencing retention in general appear to be similar in ILW-2 and ILW-1 (plasma energy deposited on Tile 1, Be deposition rate and thickness). The residual reason explaining the D amounts would be the ILW-2 finishing off with the H campaign.

Fig. 6 represents the NRA resolved impurity profiles along Tile 4 obtained after ILW-1 and ILW-2. In ILW-1 (Fig. 6(a)) the deposits are formed broadly around the strike point, and the $\mathrm{D}$ retention correlates with the deposition. In ILW-2 (Fig. 6(b)) the ISP was predominantly on Tile 4, which can be seen as an increase on the thickness of the deposit. The deposit is formed in the vicinity of the strike point and increasing towards the inner corner of the divertor. Due to higher deposited energy in ILW-2 (Table I) there is an obvious minimum in D retention near the ISP. The position of the minimum appears to be $<2.5$ $\mathrm{cm}$ away from the ISP maximum towards the private flux region. Possible reasons for this discrepancy may be e.g. the accuracy of the strike point location (up to $2-3 \mathrm{~cm}$ ), or the natural strike point sweeping due to Edge Localized Modes (ELMs) inducing a pulsating strike point movement towards the private flux region [26]. The energetic ELMs can induce the surface temperature rise locally at the divertor target, which results in D outdiffusion from the tile surface and subsurface. In Ref. [27] it was shown the temperature rise reaching up to $1400^{\circ} \mathrm{C}$ at the strike points during a plasma discharge.

\section{B. Outer divertor}

The OSP was on Tile 5 in ILW-1 and on Tile 6 in ILW-2. Hence, after ILW-2 the deposition and the $\mathrm{D}$ retention patterns on Tile 6 have similar features as was observed on Tile 4 after ILW-2: the deposition is outside the strike point increasing towards the 

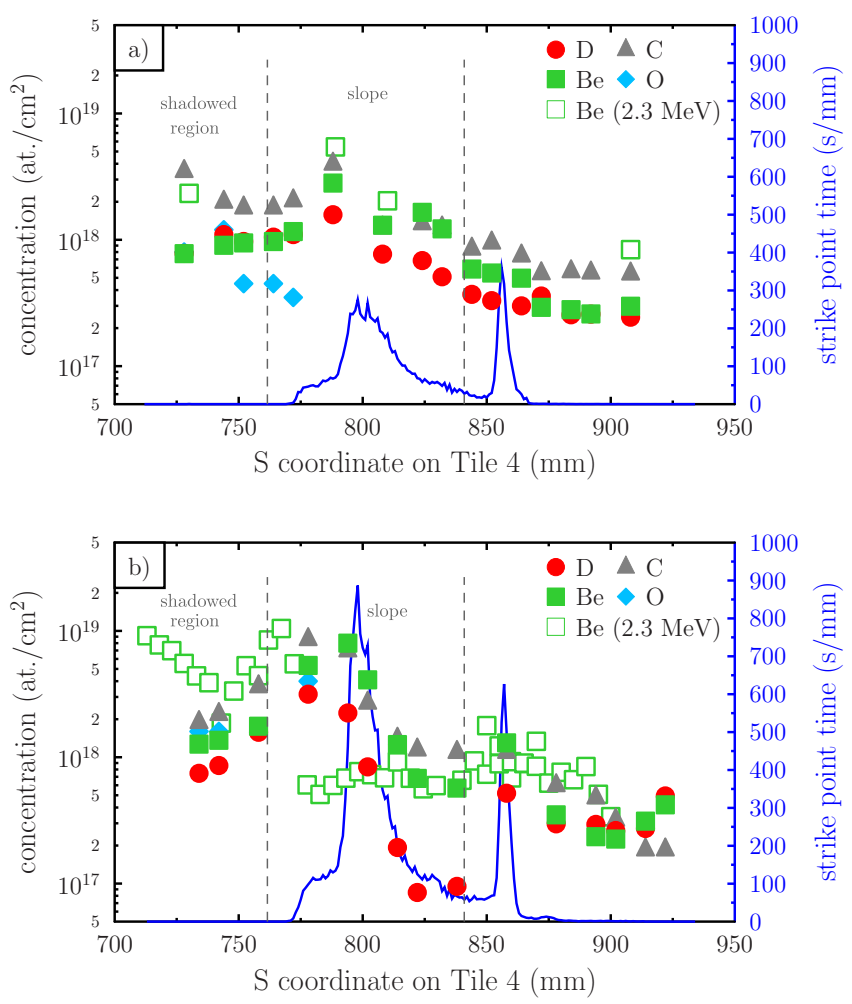

FIG. 6: (Color online) Poloidal distribution of the main impurities on Tile 4 as obtained with NRA using 4.5 $\mathrm{MeV}^{3} \mathrm{He}$ beam (also shown the Be result with $2.3 \mathrm{MeV}{ }^{3} \mathrm{He}$ ). Also shown the ISP time along the tile. Fig. 6(a): NRA after ILW-1. Deposition is found on the sloping part $(\mathrm{S}=762 \ldots 840 \mathrm{~mm})$ and in the shadowed region $(\mathrm{S}=712 \ldots 762 \mathrm{~mm})$ of the tile. Deposition and D fuel retention increase outside the ISP area towards the remote region. Fig. 6(b): NRA after ILW-2. Increase in the deposition as compared to ILW-1 due to longer strike point time on Tile 4. The $\mathrm{D}$ fuel retention shows a decrease in the vicinity of the strike point induced heating (see text for details). The $\mathrm{D}$ is found in the deposits outside the strike point.

outer corner, and the $\mathrm{D}$ retention has a minimum value near the strike point. In Fig. 7 is shown SEM results obtained from the Tile 6 strike point location after ILW-1 and ILW-2. Since the strike point time on Tile 6 and the deposited energy during ILW-1 were low, a thin deposited layer of few $\mu \mathrm{m}$ was able to be formed. In ILW-2, due to higher absorbed energy, the dominant strike point location and the resulted re-erosion events on Tile 6, the deposition at the OSP was found only in the microscopical plasma-shadowed regions, such as hills and valleys due to surface roughness. The subfigure in Fig. 7(b) shows the porous features observed on these remained deposit fractions. In Fig. 8 are shown the SIMS 

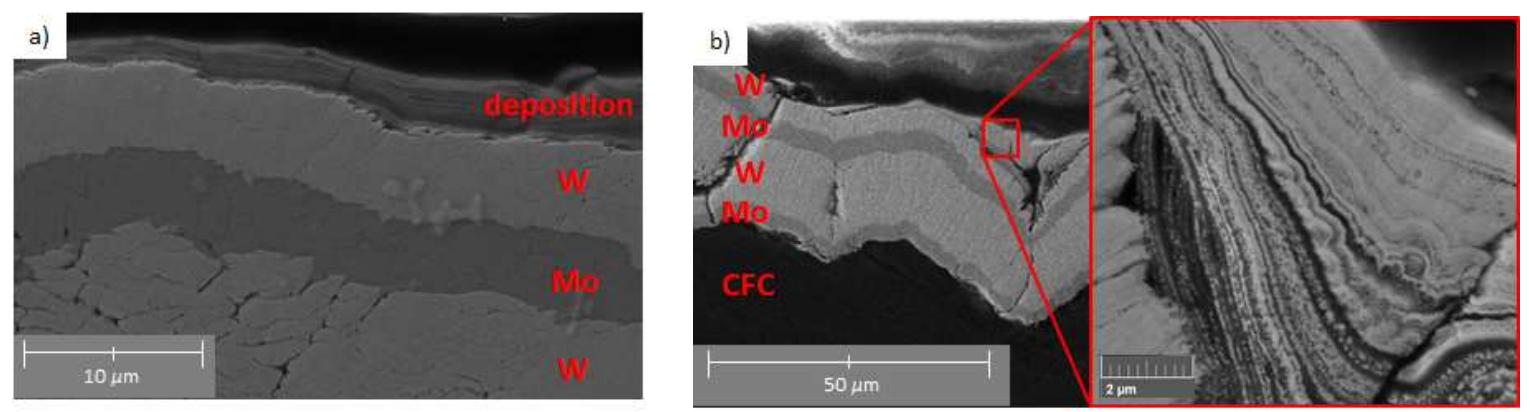

FIG. 7: SEM image on the deposition on Tile 6 sloping part $(\mathrm{S}=1475 \mathrm{~mm})$ after one campaign exposure. Fig. 7(a): After ILW-1 a layer of $\sim$ few $\mu$ m was formed. Fig. $7(\mathrm{~b})$ : During ILW-2 the location of the strike point at the sloping part resulted in re-erosion and in barely no deposition. Thin film formation is observed only in shadowed regions due to surface roughness. The magnification highlights the porous structure of these films.
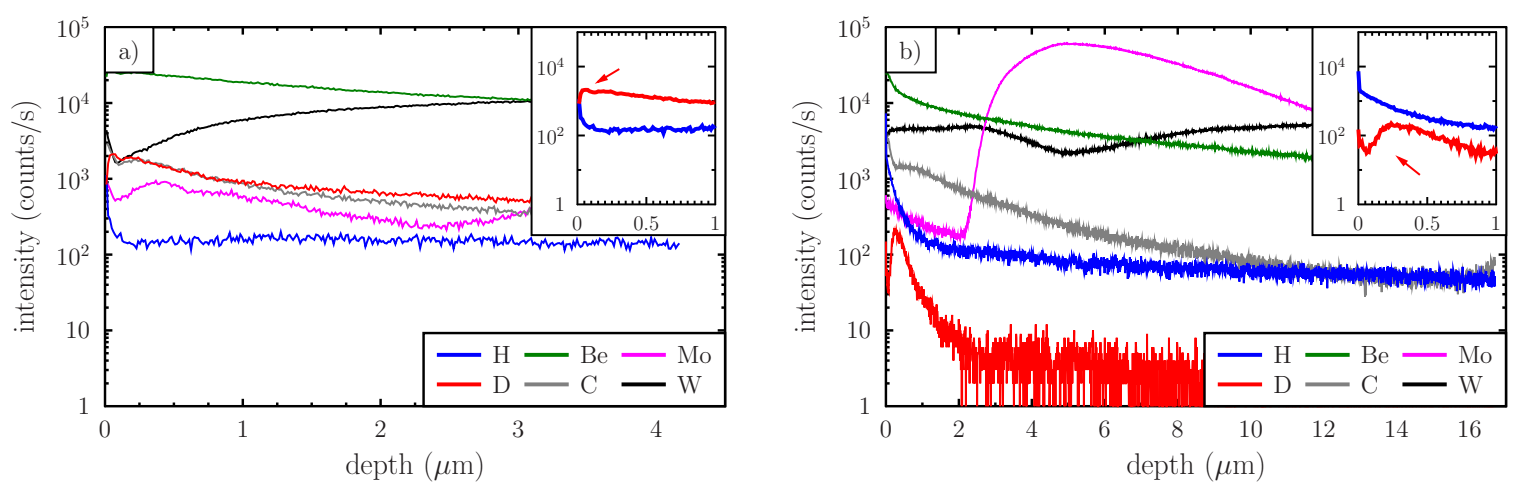

FIG. 8: (Color online) SIMS impurity concentration depth profiles for Tile 6 sloping part ( $\mathrm{S}=1475$ mm). Fig. 6(a): SIMS profiles after ILW-1. The subfigure shows a clear near-surface D retention peak (arrow). Fig. 6(b): SIMS profiles after ILW-2. Similarly to Tile 1 apron (Fig. 4(b)) the near-surface $\mathrm{D}$ profile peak is missing (arrow). The $\mathrm{H}$ co-deposition during the $\mathrm{H}$ plasma campaign induced the dip to the shape of the D profile extending up to $\sim 0.25 \mu \mathrm{m}$ from the sample surface. The low D values in ILW-2 compared to ILW-1 are due to temperature effect (Table I) and longer strike point time at the sloping part of Tile 6 in ILW-2 (Fig. 2).

impurity depth profile results from the strike point region on Tile 6. In ILW-1 no thick deposit layers were formed (Fig. 8(a)), and the D retention was low $\left(\sim 10^{18} \mathrm{D} / \mathrm{cm}^{2}\right)$. Due to the high heat on Tile 6 in ILW-2, the D amount was $1-2$ orders of magnitude less at the strike point (Fig. 8(b)). The ILW-1 SIMS profile for D shows a narrow near-surface 

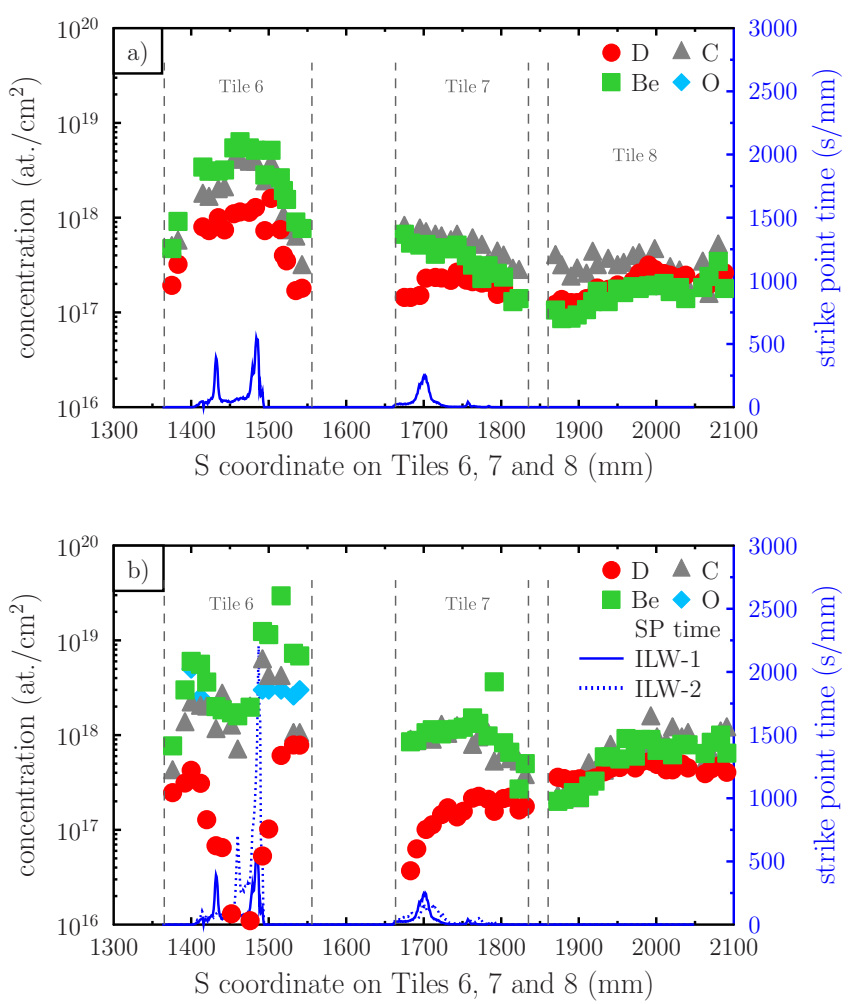

FIG. 9: (Color online) Poloidal distribution of the main impurities on Tiles 6, 7 and 8 . Also shown the OSP time along the outer divertor. Fig. 9(a): NRA after ILW-1. Deposition and D fuel retention is found in the vicinity of the ILW-1 strike point on Tile 6. Fig. 9(b): NRA on tiles exposed for two campaigns ILW-1 and ILW-2. The deposition is increased on Tiles 7 and 8 . On Tile 6 the two-campaign deposition shows an increase outside the strike point region. The D fuel retention shows a decrease at the strike points on Tiles 6 and 7 due to higher input power in ILW-2 (see Table I).

profile peak (subfigure in Fig. 8(a)). The H campaign in the end of ILW-2 has an evident effect to the observed D depth profile. As was observed with Tile 1 (Sect. III A), the D on Tile 6 has a decreased near-surface concentration, which is seen as a dip in the D depth profile (up to $\sim 0.25 \mu \mathrm{m}$ in the bulk). However, the origin of this feature on Tile 6 may be different than on Tile 1. Due to the ILW-2 OSP being located on Tile 6 and because of lack of deposition at the strike point, the retained D can be considered originating mainly due to implantation. A similar feature in the change of the D near-surface profile has been also observed on ILW-2 Tile 5 samples, which were located in the private flux region and were without deposits [13]. 
Outer divertor tiles (Tiles 6, 7, and 8) being exposed to plasmas since the beginning of the ILW project (period 2011-2014; ILW-1 and ILW-2) were analysed with 4.5 MeV NRA, and the results were compared against corresponding outer divertor tiles exposed for ILW-1 only. Fig. 9 summarizes the main findings. During the ILW-1 there was no significant OSP induced heating affecting the D retention, and only minor amounts of deposit were formed on Tiles 7 and 8 (Fig. 9(a)). The longer ILW exposure time 2011-2014, and the effect of the OSP being located on Tile 6 for longer time and with higher deposited energies in ILW-2, had a significant effect on the D retention. It is worth to note, that in the poloidal D profile on Tile 6 (Fig. 9(b)) there appears to be a D minimum approx. $2-3 \mathrm{~cm}$ from the OSP maximum towards the private flux region. The same reasoning for this discrepancy can be applied as was done for the D minimum near the ISP on Tile 4.

A D decrease was observed also on the bottom part of Tile 7 (Fig. 9(b)). Even though the Tile 7 strike point time was nearly identical in ILW-1 and ILW-2, the higher heat during ILW-2 campaign resulted in increasing the D desorption from Tile 7 during the plasma operations.

\section{SUMMARY AND CONCLUSIONS}

To summarize, divertor fuel retention and deposition properties as obtained with ILW-2 post-mortem analyses have been compared with corresponding ILW-1 results. As in ILW-1, the top horizontal surface of the inner divertor remains in ILW-2 as the region with the thickest deposition formation. The deposited layer comprises of Be with $\mathrm{C}$ and $\mathrm{O}$ being the main impurities. In ILW-1 the ISP was mainly on Tile 3. The ISP location in ILW-2 was on Tile 4, which widened the inboard SOL compared to ILW-1. This widening of SOL allowed thicker deposition formation further down on Tile 1. Moreover, it may speculated that due to higher input powers and increased main chamber erosion in ILW-2, more material migrated down to the divertor along the magnetic field lines. This was observed as an increase in the ILW-2 deposition on Tile 1 vertical surface and near the strike points on Tiles 4 and 6 . However, the high energies deposited on the divertor induced high heat at the strike point, which resulted in D outdiffusion during ILW-2 operation yielding to 1-2 orders of magnitude lower D retention at the strike point as compared to ILW-1. In general, the fuel is retained effectively in areas with low erosion and low surface temperatures hence making the high 
retention on Tile 1 and upper inner divertor feasible. Elsewhere on the divertor the retention is lower due to higher plasma interactions or lack of co-deposition. However, there are regions where the retention has been observed with D:Be concentration ratios close to unity. Such locations are further away from the high heat regions, and can be found e.g. in the remote inner and outer corners of the divertor and on the upper outer divertor. The effect of seeded impurities (N, Ne, Ar) during plasma operations is to introduce radiative impurities in the divertor allowing dissipation of plasma power density at the target. The relative total amount of seeded impurities was increased from $\sim 0.3 \%$ in ILW-1 to $\sim 4.5 \%$ in ILW-2. The effect of seeded impurities to fuel retention has been studied previously with laboratory experiments and computationally although more systematic studies for increasing the database would be required. The results show the $\mathrm{N}$ may be having a minuscule decreasing effect to $\mathrm{D}$ retention [28] and the Ar having a zero or minuscule effect on hydrogen retention [29, 30]. Analyses on the effect of seeded impurities to fuel retention trap location in JET samples is ongoing (see e.g. Ref. 31).

Unlike the ILW-1 campaign with D-only plasmas, the ILW-2 was finished with a twoweek campaign of $\mathrm{H}$ pulses. Even though the total amount of puffed D was two times higher during ILW-2 than in ILW-1, the ILW-2 post-mortem results did not show correlation in $\mathrm{D}$ retention in the thick deposit region on top of the inner divertor. Instead, the $\mathrm{H}$ codeposition resulted in near-surface accumulation of $\mathrm{H}$ instead of $\mathrm{D}$, which was seen as a concentration dip in the measured D depth profile. This near-surface accumulation of $\mathrm{H}$, and the resulting lack of near-surface D was observed poloidally throughout the divertor. However, the $\mathrm{H}$ implantation is expected to play a dominant role at the strike points, leading to a different mechanism for the retention of hydrogen isotopes than in divertor areas with co-deposition. In the co-deposited region on Tile 1 , the $\mathrm{D}$ profile was affected by $\mathrm{H}$ up to $0.5 \mu \mathrm{m}$ in depth, and at the strike point with implantation being the dominant retention mechanism up to $0.25 \mu \mathrm{m}$.

Analyses on outer divertor tiles being exposed for both ILW-1 and ILW-2 showed a nearly linear accumulation of deposition in regions outside of strike point. The $\mathrm{D}$ retention was observed to be strongly dependent on the ILW-2 strike point location. The absorbed high powers enhances the $\mathrm{D}$ outdiffusion at the strike point, and fuel is found to be retained in the neighbourhood of the strike point. Deposit formation at the strike point is decreased due to increased re-erosion processes. 
The reported results are part of ongoing analysis work on ILW-2 and ILW-1 \& ILW-2 exposed divertor tiles, and hence no global trends can be presently assessed. However, main differences originating from the ILW-1 and ILW-2 plasma operations are evident. Operating plasmas producing high energy deposition on the divertor lead to decrease in fuel retention and deposit formation at the strike points. Effect of H-only plasmas is seen as decrease of the $\mathrm{D}$ fuel retention in the near-surface regions of the plasma-facing components.

\section{Acknowledgments}

This work has been carried out within the framework of the EUROfusion Consortium and has received funding from the Euratom research and training programme 2014-2018 under grant agreement No 633053. The views and opinions expressed herein do not necessarily reflect those of the European Commission.

[1] G. F. Matthews, P. Edwards, T. Hirai, M. Kear, A. Lioure, P. Lomas, A. Loving, C. Lungu, H. Maier, P. Mertens, et al., Phys. Scripta T128, 137 (2007).

[2] S. Brezinsek, T. Loarer, V. Philipps, H. Esser, S. Grünhagen, R. Smith, R. Felton, J. Banks, P. Belo, A. Boboc, et al., Nucl. Fusion. 53, 083023 (2013).

[3] A. Widdowson, E. Alves, C. F. Ayres, A. Baron-Wiechec, S. Brezinsek, N. Catarino, J. P. Coad, K. Heinola, J. Likonen, G. F. Matthews, et al., Phys. Scripta T159, 014010 (2014).

[4] J. P. Coad, E. Alves, N. P. Barradas, A. Baron-Wiechec, N. Catarino, K. Heinola, J. Likonen, M. Mayer, G. F. Matthews, P. Petersson, et al., Phys. Scripta T159, 014012 (2014).

[5] K. Heinola, A. Widdowsona, J. Likonen, E. Alves, A. Baron-Wiechec, N. Barradas, S. Brezinsek, N. Catarino, P. Coad, S. Koivuranta, et al., Phys. Scripta T167, 014075 (2016).

[6] J. Likonen, K. Heinola, A. D. Backer, S. Koivuranta, A. Hakola, C. F. Ayres, A. BaronWiechec, P. Coad, G. F. Matthews, and A. Widdowson, Phys. Scripta T167, 014074 (2016).

[7] M. Mayer, S. Krat, W. van Renterghem, A. Baron-Wiechec, S. Brezinsek, I. Bykov, P. Coad, Y. Gasparyan, K. Heinola, J. Likonen, et al., ps T167 (2016).

[8] H. Bergsåker, I. Bykov, Y. Zhou, P. Petersson, G. Possnert, J. Likonen, S. Koivuranta, , and A. Widdowson, Phys. Scripta T167 (2016). 
[9] A. Widdowson, E. Alves, A. Baron-Wiechec, N. Barradas, N. Catarino, J. P. Coad, V. Corregidor, A. Garcia-Carrasco, K. Heinola, S. Koivuranta, et al., Nuclear Materials and Energy (2017), in press.

[10] A. Widdowson, A. Baron-Wiechec, P. Batistoni, E. Belonohy, J. P. Coad, P. Dinca, F. Fox, K. Heinola, I. Jepu, J. Likonen, et al., Phys. Scripta T167, 014057 (2016).

[11] A. Lahtinen, J. Likonen, S. Koivuranta, A. Hakola, K. Heinola, C. F. Ayres, A. Baron-Wiechec, J. P. Coad, A. Widdowson, and J. Raisanen, Nuclear Materials and Energy (2017), in press.

[12] N. Catarino, N. P. Barradas, V. Corregidor, A. Widdowson, A. Baron-Wiechec, J. P. Coad, K. Heinola, M. Rubel, and E. Alves, Nuclear Materials and Energy (2016), in press.

[13] S. Krat, M. Mayer, A. Baron-Wiechec, Y. Gasparya, K. Heinola, I. Jepu, C. Ruset, G. de SaintAubin, and A. Widdowson (2017), in preparation.

[14] E. Joffrin, M. Baruzzo, M. Beurskens, C. Bourdelle, S. Brezinsek, J. Bucalossi, P. Buratti, G. Calabro, C. Challis, M. Clever, et al., Nucl. Fusion. 54, 013011 (2014).

[15] F. Romanelli and on behalf of JET Contributors, Nucl. Fusion. 55, 104001 (2015).

[16] M. Mayer, SIMNRA User's Guide 6.05 (Max-Planck-Institut für Plasmaphysik, Garching, Germany, 2009), http://home.rzg.mpg.de/ mam/index.html.

[17] S. Krat, M. Mayer, I. Bykov, C. P. Lungu, G. de Saint Aubin, A. Widdowson, and I. S. Carvalho, Nuclear Materials and Energy 11, 20 (2017).

[18] N. P. Barradas and C. Jeynes, Nucl. Instr. Meth. Phys. Res. B 266, 1875 (2008).

[19] J. Likonen, E. Alves, A. Baron-Wiechec, S. Brezinsek, J. P. Coad, A. Hakola, K. Heinola, S. Koivuranta, G. F. Matthews, P. Petersson, et al., Phys. Scripta T159, 014016 (2014).

[20] K. Heinola, T. Ahlgren, E. Vainonen-Ahlgren, J. Likonen, and J. Keinonen, Phys. Scripta T128, 91 (2007).

[21] J. Likonen, K. Heinola, A. D. Backer, S. Koivuranta, C. F. Ayres, A. Baron-Wiechec, P. Coad, I. Jepu, G. F. Matthews, and A. Widdowson (2017), in preparation.

[22] M. Mayer, S. Krat, A. Baron-Wiechec, Y. Gasparyan, K. Heinola, S. Koivuranta, J. Likonen, C. Ruset, G. de Saint-Aubin, and A. Widdowson (2017), in preparation.

[23] K. Heinola, C. F. Ayres, A. Baron-Wiechec, J. P. Coad, J. Likonen, G. F. Matthews, and A. Widdowson, Phys. Scripta T159, 014013 (2014).

[24] A. Baron-Wiechec, A. Widdowson, E. Alves, C. F. Ayres, N. P. Barradas, S. Brezinsek, J. P. Coad, N. Catarino, K. Heinola, J. Likonen, et al., J. Nucl. Mater. 463 (2015). 
[25] S. Brezinsek, A. Widdowson, M. Mayer, V. Philipps, P. Baron-Wiechec, J. W. Coenen, K. Heinola, A. Huber, J. Likonen, P. Petersson, et al., Nucl. Fusion. 55, 063021 (2015).

[26] C. Guillemaut (2017), private communication.

[27] S. Brezinsek, S. Wiesen, D. Harting, C. Guillemaut, A. J. Webster, K. Heinola, A. G. Meigs, M. Rack, Y. Gao, G. Sergienko, et al., Phys. Scripta T167, 014076 (2016).

[28] M. Oberkofler and C. Linsmeier, Nucl. Fusion. 50, 125001 (2010).

[29] M. Baldwin, R. Doerner, W. Wampler, D. Nishijima, T. Lynch, and M. Miyamoto, Nucl. Fusion. 51, 103021 (2011).

[30] K. Heinola and T. Ahlgren, J. Nucl. Mater. 438, S1001 (2013).

[31] M. Tokitani, M. Miyamoto, S. Masuzaki, R. Sakamoto, Y. Oya, Y. Hatano, T. Otsuka, M. Oyaidzu, H. Kurotaki, T. Suzuki, et al., Fusion Eng. Design (2017), submitted. 
TABLE I: Main characteristics of the plasmas during the ILW-1 and ILW-2 campaings.

\begin{tabular}{|c|c|c|}
\hline & ILW-1 (2011-2012) & ILW-2 (2013-2014) \\
\hline limiter phase & $6 \mathrm{hrs}$ & $5.2 \mathrm{hrs}$ \\
\hline divertor phase & $13 \mathrm{hrs}$ & $14.2 \mathrm{hrs}$ \\
\hline hydrogen $(\mathrm{H})$ campaign & none & $0.6 \mathrm{hrs}$ \\
\hline \multicolumn{3}{|l|}{ gas inventory (atoms) } \\
\hline $\mathrm{H}^{*}$ & $\sim 2.7 \times 10^{24}$ & $\sim 3.3 \times 10^{25}$ \\
\hline $\mathrm{H}_{\text {campaign }}^{\dagger}$ & none & $\sim 2.2 \times 10^{25}$ \\
\hline $\mathrm{D}^{*}$ & $\sim 2.8 \times 10^{26}$ & $\sim 6.3 \times 10^{26}$ \\
\hline $\mathrm{N}^{\S}$ & $\sim 9.8 \times 10^{23}$ & $\sim 9.7 \times 10^{24}$ \\
\hline $\mathrm{Ne} \S$ & $\sim 1.5 \times 10^{21}$ & $\sim 4.0 \times 10^{23}$ \\
\hline $\operatorname{Ar} \S$ & $\sim 1.2 \times 10^{21}$ & $\sim 2.0 \times 10^{25}$ \\
\hline inner strike point ${ }^{\ddagger}$ & Tile 3 & Tile 4 \\
\hline outer strike point ${ }^{\ddagger}$ & Tile 5 & Tile 6 \\
\hline total absorbed energy** & & \\
\hline Tile 1 & 4.9 GJ & 5.8 GJ \\
\hline Tile 3 & 4.9 GJ & 5.9 GJ \\
\hline Tile 4 & $1.2 \mathrm{GJ}$ & 4.2 GJ \\
\hline Tile 5 & no data & no data \\
\hline Tile 6 & 5.5 GJ & 20.0 GJ \\
\hline Tile 7 & 4.2 GJ & 15.1 GJ \\
\hline Tile 8 & 3.2 GJ & 5.2 GJ \\
\hline
\end{tabular}

* includes restart pulses, gas and pellet injections, neutral beam heating, and disruption protection system puffs.

${ }^{\dagger}$ puffed fuel during $\mathrm{H}$ campaign only.

$\S$ includes restart pulses, gas and pellet injections, and disruption protection puffs.

$\ddagger$ predominant strike point location. Detailed strike point distribution shown in Fig. 2.

** thermocouple measurement. 